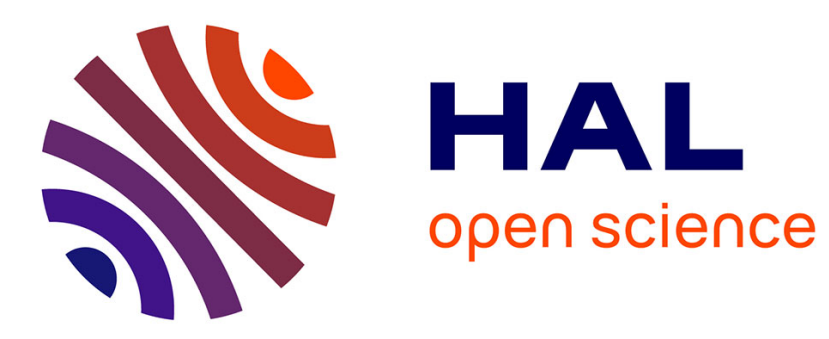

\title{
Modeling of a new SMA Microactuator for active endoscopy applications.
}

\author{
Joël Abadie, Nicolas Chaillet, Christian Lexcellent
}

\section{To cite this version:}

Joël Abadie, Nicolas Chaillet, Christian Lexcellent. Modeling of a new SMA Microactuator for active endoscopy applications.. 12th IFAC Symposium on Information Control Problems in Manufacturing, INCOM'06., May 2006, Saint-Etienne, France. pp.161-166. hal-00331650

\section{HAL Id: hal-00331650 \\ https://hal.science/hal-00331650}

Submitted on 17 Oct 2008

HAL is a multi-disciplinary open access archive for the deposit and dissemination of scientific research documents, whether they are published or not. The documents may come from teaching and research institutions in France or abroad, or from public or private research centers.
L'archive ouverte pluridisciplinaire HAL, est destinée au dépôt et à la diffusion de documents scientifiques de niveau recherche, publiés ou non, émanant des établissements d'enseignement et de recherche français ou étrangers, des laboratoires publics ou privés. 


\title{
MODELING OF A NEW SMA MICROACTUATOR FOR ACTIVE ENDOSCOPY APPLICATIONS
}

\author{
J. Abadie* N. Chaillet* C. Lexcellent ${ }^{* *}$ \\ * Laboratoire d'Automatique de Besançon UMR CNRS \\ 6596 - ENSMM - Université de Franche-Comté, France \\ ** FEMTO-ST Laboratoire de Mécanique Appliquée R. \\ Chaléat UMR CNRS 6174-ENSMM - Université de \\ Franche-Comté, France
}

\begin{abstract}
Shape Memory Alloys (SMA) are good candidates to actuate endoscope heads but the cooling problem must be solved particularly in confined situations. For these reasons, a new SMA microactuator specially designed for active endoscopy applications has been developed in our laboratory. This work is a new step in the approach of using integrated thermoelectric cooling with SMA actuators. In fact, the Peltier effect is very attractive in such a case because this reversible phenomenon reduces the overheating of the external environment and provides forced cooling that decreases the response time. In this paper the actuator design and its working principle are presented. A fine modeling of the coupled mechanical and thermal behaviours gives a better understanding of the physical phenomenon involved in the actuator. Finally an experimental prototype has been developed and tested in order to verify the model predictions. Copyright (c) 2006 IFAC.
\end{abstract}

Keywords: Shape memory alloys, active endoscopy, thermoelectricity, modeling.

\section{INTRODUCTION}

Microtechnology and microsystems engineering require new active materials. These materials are often used to develop micro-actuators and microsensors. In this category of materials, Shape Memory Alloys (SMAs) are good candidates for microactuation. SMA wires, or thin plates, can actuate microrobots and are able to provide very significant forces, but have low dynamic response, especially for cooling.

The control of the SMA phases transformations, and then the mechanical power generation, is driven by the temperature of the material. Classically Joule effect is an easy way to heat the SMA actuators, but cooling is made by an other way (typically by natural convection or conduction). Unfortunately, endoscopic applications involve confined environments with a low convection capabilities and a variable external temperature. Moreover, the dynamic response of the actuator depends on cooling capabilities. The work of J. Szewczyk et al. shows the difficulties to cool the SMA when it is integrated in a flexible head (Szewczyk et al., 2001). For these reasons, we have examined a reversible way of heating and cooling SMA micro-actuators, based on the thermoelectric effect, e.g. the Peltier effect.

Even if it is often bad known and rarely used, the implementation of thermoelectric elements has already been performed for the temperature control of shape memory alloys. Several investi- 


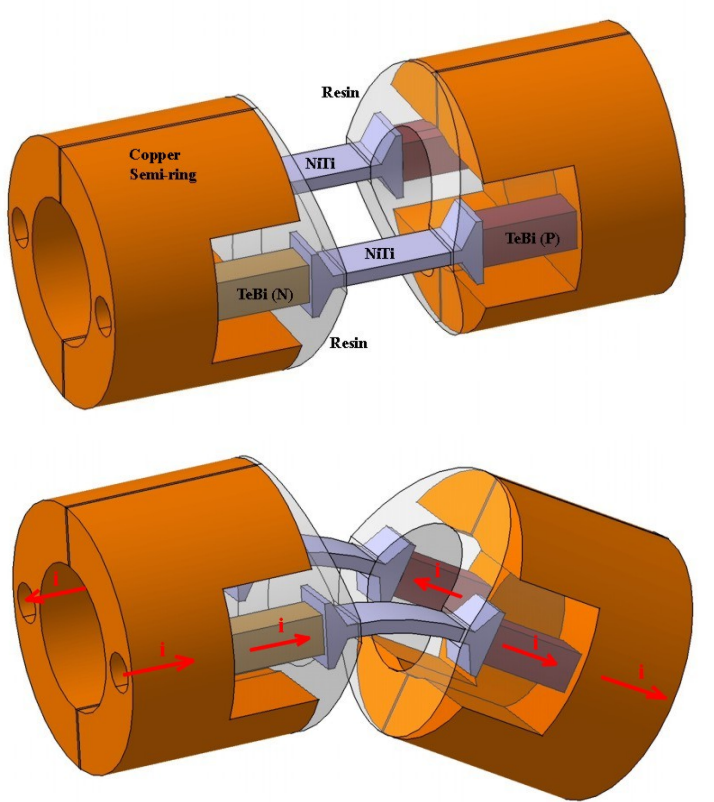

Fig. 1. Actuator constitution (up), electrically supplied actuator (down).

gations and developments that use thermoelectric coolers in this field have shown that it can work efficiently (Thrasher et al., 1992; Semenyuk et al., 1998; Khan et al., 2003). In these particular cases, the SMA actuator and the thermoelectric cooler are separated and calorific energy exchanges, between them, are done by thermal conduction. However, it seems that the best results are obtained, when choosing the maximal integration of the thermoelectric phenomenon (Bhattacharyya et al., 1995; Lagoudas and Ding, 1995). In this case, the thermoelectric connections are directly made on the SMA element. A thermal model has already been validated by an experimental thermoelectric system which is described in a previous paper (Abadie et al., 1999). The development of a basic thermoelectric actuator in our laboratory has demonstrate the interest of the Peltier effect in temperature control of NiTi (Abadie et al., 2002). The goal of the present paper is to describe and model a new thermoelectric SMA micro-actuator specially designed for endoscopic applications.

\section{ACTUATOR DESCRIPTION}

\subsection{General description}

The developed actuator is composed of two elementary stages symmetrically assembled (see figure 1). Each stage is sequentially composed of a copper semi-ring, a $\mathrm{Bi}_{2} \mathrm{Te}_{3} \mathrm{~N}$ doped ingot, a NiTi blade, a $\mathrm{Bi}_{2} \mathrm{Te}_{3} \mathrm{P}$ doped ingot and a second copper semi-ring. Finally, the actuator dimensions are: $4 \mathrm{~mm}$ in diameter, $9 \mathrm{~mm}$ in length and the NiTi blade itself has $200 \mu m$ in thickness.
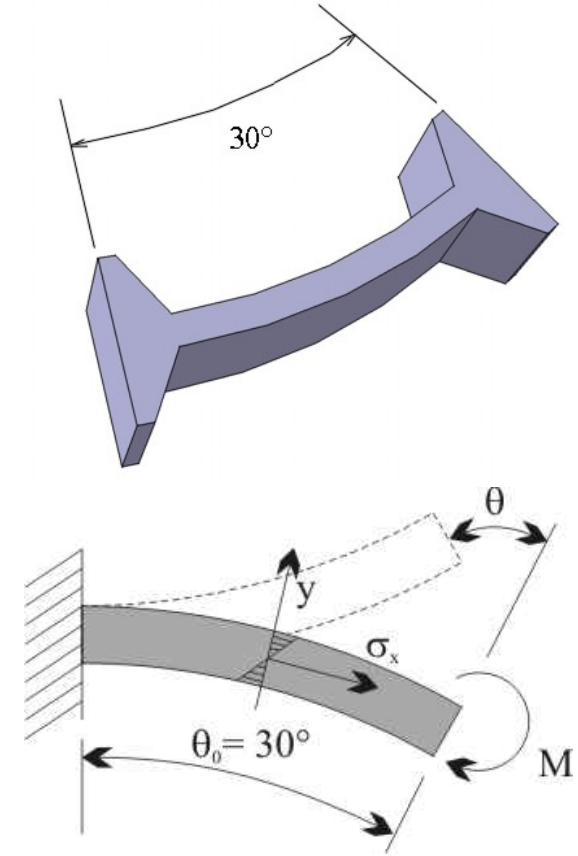

Fig. 2. Niti blade in austenite phase (up), blade model parameters (down).

When the actuator is supplied with a $0.6 \mathrm{~A}$ current, the blades are bending. They produce a measured angle $\theta$ of about $25^{\circ}$. When the current is inverted, a symmetric deflection is obtained. The reached deflection after the current application is maintained even when the current is removed. To obtain this kind of behaviour, we had to design the actuator with a special blade configuration with a thermal control performed by an integrated Peltier system. So, the phase transformation of the SMA blades is driven by the heat transfers produced by the thermoelectric system.

\subsection{Mechanical principle}

In the actuator, the two blades have an antagonist behaviour. First, the blades are machined with an initial curvature of $30^{\circ}$ (corresponding to the shape in the austenitic phase), in a SMA material for which the temperature transformation is above the room temperature (see figure 2 ). Then they are anti-symmetrically positioned in the actuator such as when a blade is heated to austenite, it shape memory effect occurs and produces a martensite reorientation in the cold antagonist blade (push-pull working). Only one blade can be heated at the same time. One way displacement is obtained by heating the first blade and the reverse displacement by the second one. In this configuration the actuated blade is not able to completely reorient the other blade (not actuated). For this reason, the displacement range is lower than $60^{\circ}$. Practically a range of $40^{\circ}$ is possible when the austenite phase transformation is completed in a blade. 


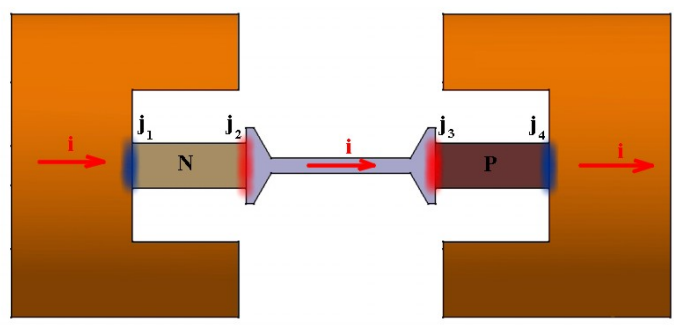

Fig. 3. Thermoelectric principle in an elementary stage.

\subsection{Thermoelectric system}

The maximum integration of the thermoelectric system consists in placing thermoelectric junctions directly between the copper semi-rings, the $\mathrm{TeBi}$ ingots and the NiTi blade in each elementary stage. By this way, four junctions $j_{1}, \ldots, j_{4}$ are activated by the going through current (see figure $3)$. For a positive current $i$, the junctions $j_{1}$ and $j_{4}$ produce heat while $j_{2}$ and $j_{3}$ absorb heat. If $i$ is negative, heat production/absorption is inverted due to the fact that the Peltier effect is a reversible phenomenon.

\section{ACTUATOR MODELING}

With this SMA actuator, a complex thermomechanical coupling must be taken into account. To simplify, we have split the study in two parts. First, the mechanical behaviour of one NiTi blade is investigated in order to determine the stress and the strain in the SMA material. Then, thermal modeling for temperature prediction is performed considering the blade as a passive material.

\subsection{SMA bending model}

A phenomenological approach is used to model the SMA blade (Leclercq and Lexcellent, 1996). It is based on the Helmholtz free energy expression of the different phases mixture: austenite, self accommodating martensite and stress induced martensite (Benzaoui et al., 1997). This approach gives a prediction of the one-dimension SMA behaviour, e.g. when and how phase transformation occurs under thermal and strain solicitations. Bending is solved by using a spatial discretization of the blade. More details can be found in (Abadie et al., 2004). To summarize, the blade is considered as a stack of thin Niti layers. The onedimension model is applied at each layer assuming that the layer deformation $\varepsilon_{x}(y)$ situated at the distance $y$ of the neutral axis is:
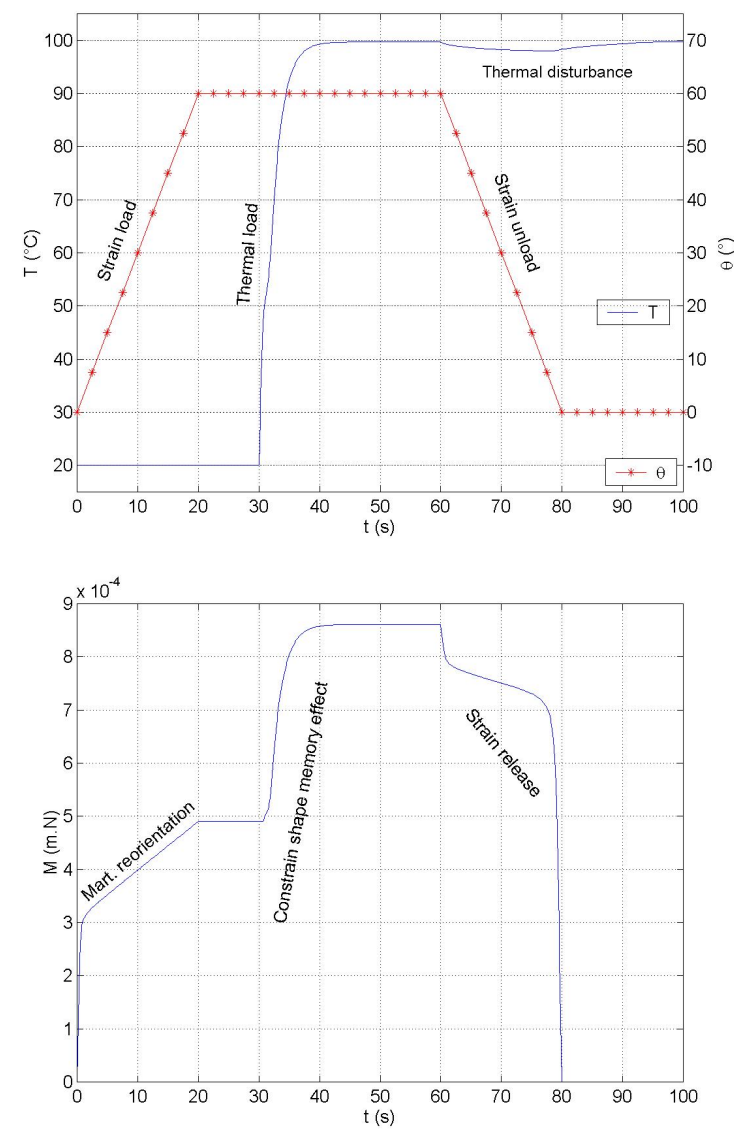

Fig. 4. Model input signals (up), calculated bending momentum (down).

$$
\varepsilon_{x}(y)=\frac{y \theta}{l}=y k
$$

where $l$ is the blade length, $\theta$ is its extremity rotation angle and $k$ its curvature assuming a circular bending (see figure 2). The stress in the layer is calculated using:

$$
\sigma_{x}(y)=E\left(\varepsilon_{x}(y)-\gamma z_{\sigma}(y)\right)
$$

where $\gamma$ and $z_{\sigma}$ are respectively the SMA maximum plastic deformation and the volume fraction of stress induced martensite. $E$ is the average Young modulus of the material. The heat equation used to determine the temperature $T$ of the blade is:

$$
\rho\left(c_{v} \dot{T}-\Delta u \dot{z}\right)=q+\lambda \triangle T
$$

where $\Delta u, q, \lambda, z$ and $\Delta T$ are respectively the phase transformation latent heat, the thermal power applied, the thermal conductivity, the total volume fraction of martensite (volume fraction of self accommodating martensite $z_{t}+$ stress induced martensite $z_{\sigma}$ ) and the temperature laplacian. 

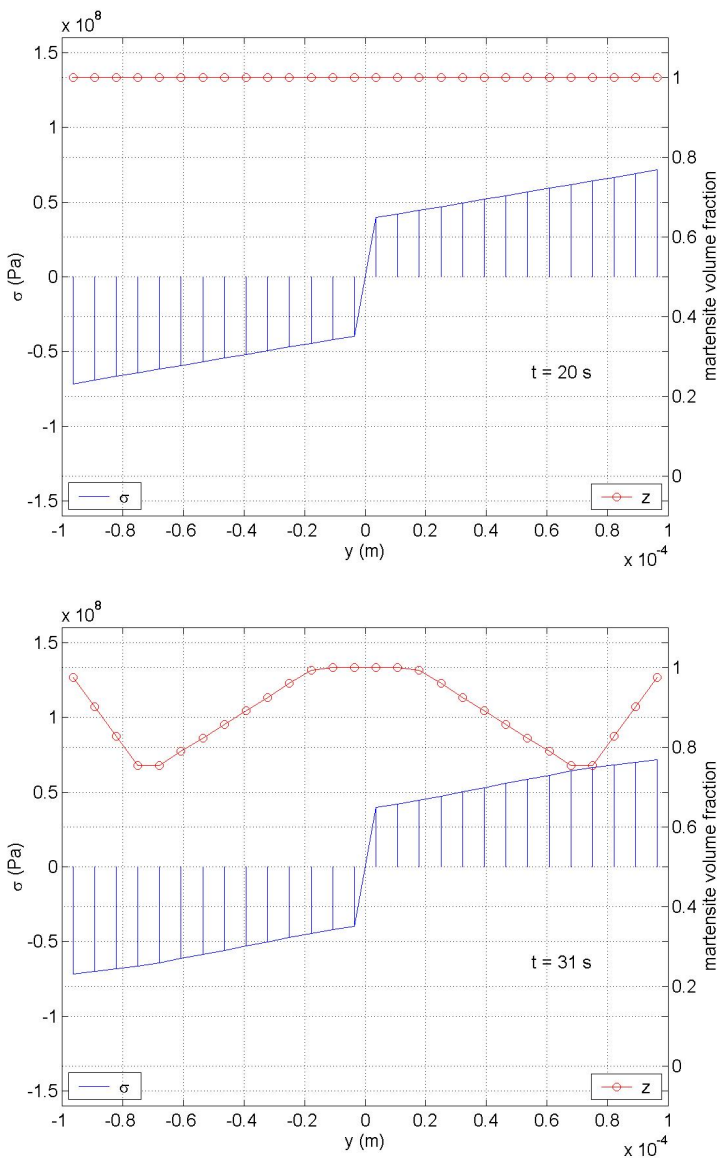

Fig. 5. Martensite and stress evolution during thermal load.

We have used Matlab/Simulink to calculate the model response in the case of a blade of $2 \mathrm{~mm}$ in length, $0.8 \mathrm{~mm}$ in wideness, $0.2 \mathrm{~mm}$ in thickness and with an initial angle $\theta_{0}=30^{\circ}$. The stress free state austenite and martensite start temperatures are respectively $A_{s}=52^{\circ} \mathrm{C}$ and $M_{s}=38^{\circ} \mathrm{C}$, the maximum pseudoplastic deformation is $\gamma=0.05$. In this model, the input are the thermal power $q$ and the rotation angle $\theta$. The natural convection and Joule effect are the two physical phenomenon introduced in $q$. The room temperature and self accommodating martensite fraction $z_{t}$ are taken as the initial conditions of the blade. The simulation consists in applying an imposed strain, a thermal load and a strain unload (see figure 4 (up)).

The imposed strain load occurs at the beginning of the simulation and has $20 \mathrm{~s}$ of duration. It corresponds to the martensite reorientation. The bending momentum $M_{r}$ increases and reaches 4.9.10 ${ }^{-4}$ N.m. At $t=20 \mathrm{~s}$, the stress distribution is shown on figure 5 (up). During the load, the martensite volume fractions remains equal to 1. At $t=30 \mathrm{~s}$, the thermal load occurs and generates the phase transformation. It begins from the blade skin and spreads to the neutral fiber (see figure 5 (down) and 6 (up)). At $t=60 \mathrm{~s}$, the constrained memory effect bending momentum $M_{c}$ reaches
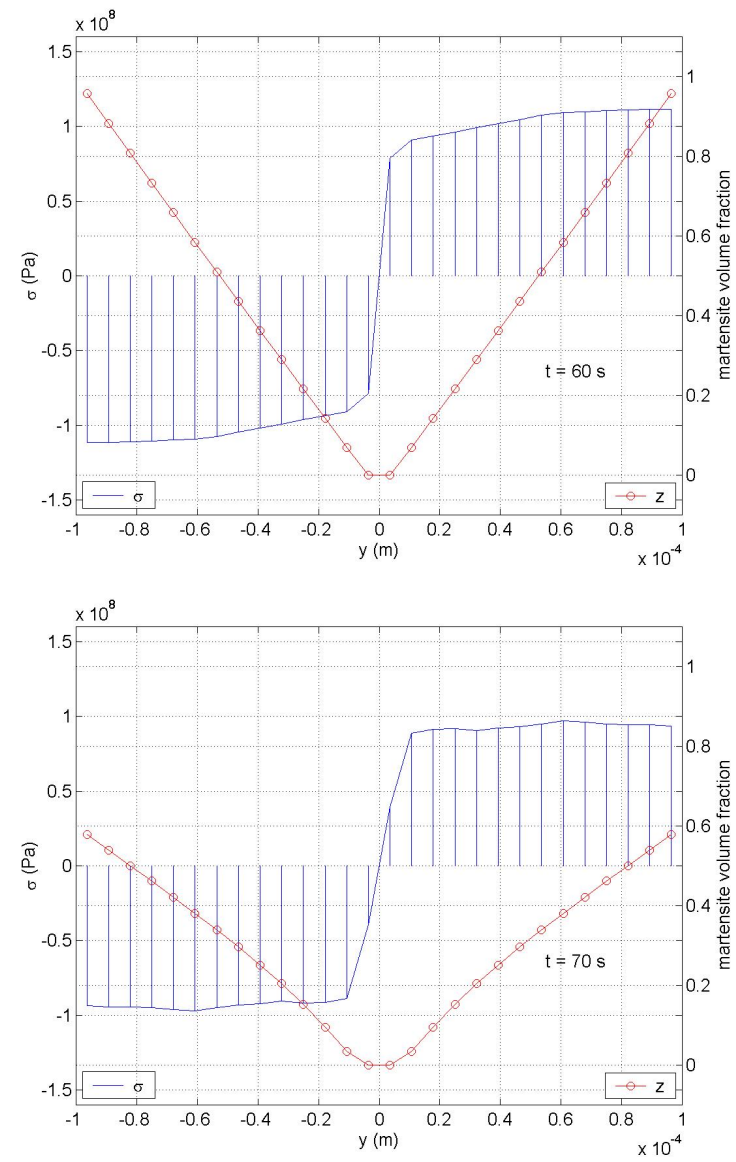

Fig. 6. Martensite and stress evolution during mechanichal unload.

$8.6 .10^{-4}$ N.m. Consequently the useful momentum for the actuator is the difference between $M_{c}$ and $M_{r}$. At $t=60 \mathrm{~s}$, the strain unload occurs which induces the martensite transformation and produces a thermal disturbance (see figure 4 (up)). The calculated rotation angle is then $\theta_{u}=3^{\circ}$ when the bending momentum is equal to $M_{r}$. In fact, the actuator useful range is $\theta_{\max }=54^{\circ}$.

\subsection{Modeling of the complete thermoelectric system}

To determine the thermal behaviour of the actuator, one has to consider the copper rings, the TeBi ingots and the SMA blades (let us note that the SMA latent heat is not involved in the reorientation process):

$$
\rho c_{v} \dot{T}=q+\lambda \triangle T
$$

The internal heat source $q$ is zero for the rings and $q=\rho_{e} j^{2}$ for the ingots and the blades. The thermal conductivity $\lambda$, the electric resistance $\rho_{e}$ and the material density $\rho$ are given in the table 1 .

The Peltier effect is taken into account as a heat flux discontinuity $\phi$ in the junctions between copper, TeBi and NiTi. This heat flux is: 
Table 1. Thermal parameters.

\begin{tabular}{lccc} 
& $\rho_{e}(\Omega \cdot m)$ & $\rho\left(\mathrm{kg} \cdot \mathrm{m}^{-3}\right)$ & $\lambda\left(W \cdot \mathrm{m}^{-1} \cdot \mathrm{K}^{-1}\right)$ \\
\hline Copper & 0 & 8700 & 400 \\
NiTi & $6,3.10^{-7}$ & 6500 & 22 \\
TeBi & $1,0.10^{-7}$ & 7530 & 1,61 \\
\hline
\end{tabular}

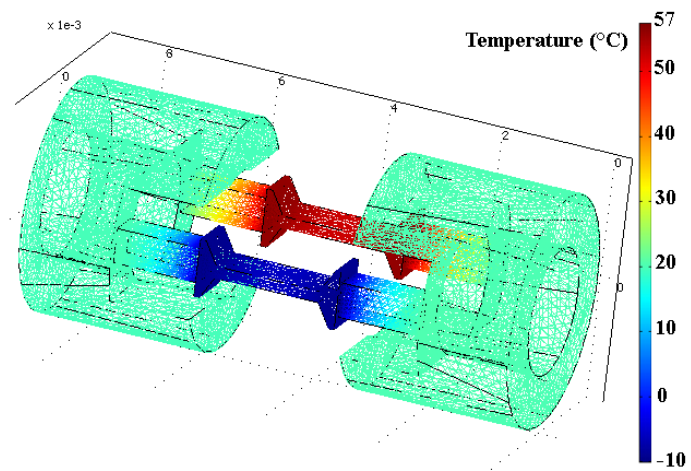

Fig. 7. Stationary state solution.

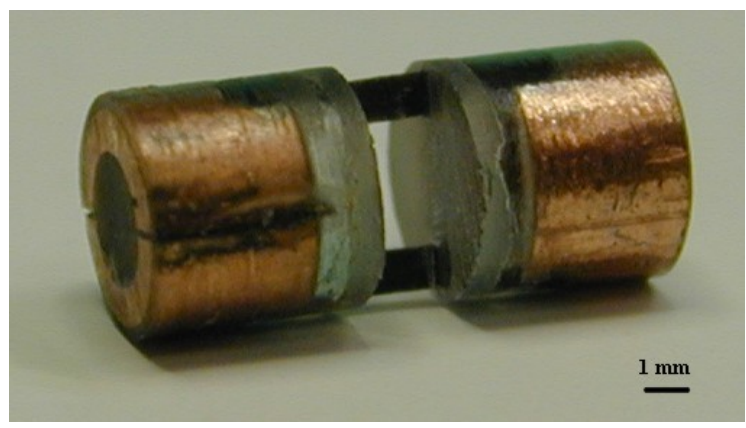

Fig. 8. Developed actuator.

$$
\phi_{j_{1}, j_{4}}=\pi j \text { and } \phi_{j_{2}, j_{3}}=-\pi j
$$

where $\pi$ is the Peltier coefficient of the ingots $\left(\pi=5 \cdot 6 \cdot 10^{-2}\right.$ Volt $)$.

The equations are solved using the 3D heat transfer by conduction module from Comsol Multiphysics. The boundaries conditions are set as a natural convection with a heat transfer coefficient $h=425 \mathrm{~W} \cdot \mathrm{m}^{-2}$ and a room temperature of $20^{\circ} \mathrm{C}$. The current applied to the actuator is $i=0.6 \mathrm{~A}$. The steady state solution shows an homogeneous temperature in the blades and in the copper rings (see figure 7). Moreover the rings temperature remains at the room temperature and only the blades are heated and cooled. The reached temperature is $57^{\circ} \mathrm{C}$ for the hot blade and $-10^{\circ} \mathrm{C}$ for the cold one.

\section{EXPERIMENTAL RESULTS}

An experimental actuator has been made and tested in order to validate the simulation results (see figure 8). The temperature measurements have been made using Chromel/Alumel microthermocouples with $25 \mu \mathrm{m}$ in diameter wires. A first thermocouple was glued on one copper

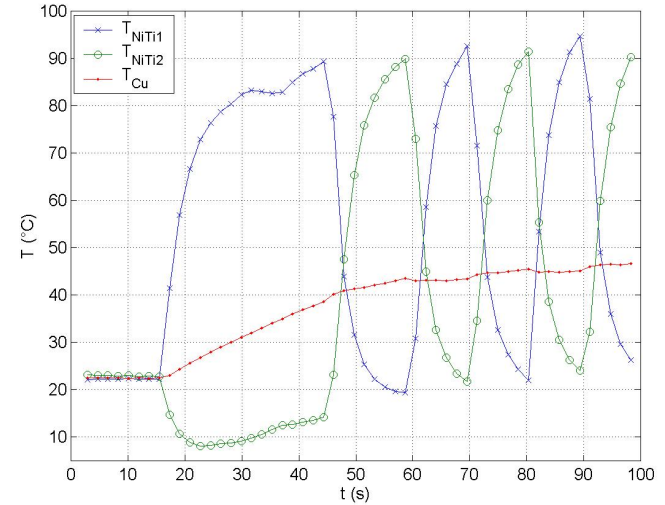

Fig. 9. Temperature measurement under current steps.

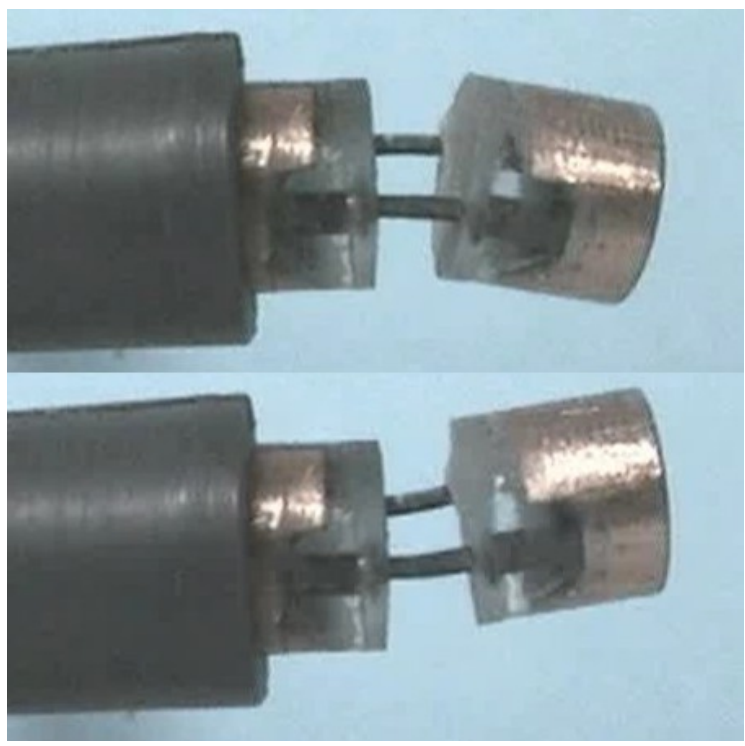

Fig. 10. Position for $i=0,6 \mathrm{~A}(\mathrm{up})$ and $-0,6 \mathrm{~A}$ (down)

ring and two others in the middle of each $\mathrm{NiTi}$ blade. Figure 9 shows the temperature evolution under current steps. At the beginning of the measurement, when no current is applied the three thermocouples indicates the room temperature $\left(22^{\circ} \mathrm{C}\right)$. At $t=16 \mathrm{~s}$, a current step of $0.6 \mathrm{~A}$ produces respectively in the blade 1 and 2 a temperature increase and decrease as predicted by the simulation. In the same time, the copper temperature slowly increases and finally reaches $46^{\circ} \mathrm{C}$. This unwanted phenomenon is probably due to a lower convection than the model estimation but mainly to a high contact resistance (which increases the Joule effect) in the thermoelectric junctions of the tested prototype. It shows that a particular attention is required to make the solders between the TeBi ingots and the others elements. Our soldering method should be reviewed. At $t=45 \mathrm{~s}$, the current is inverted to $-0.6 \mathrm{~A}$ and respectively produces in the blade 1 and 2 a temperature decrease and increase. The gap between the hot and the cold blade is $75^{\circ} \mathrm{C}$ in 


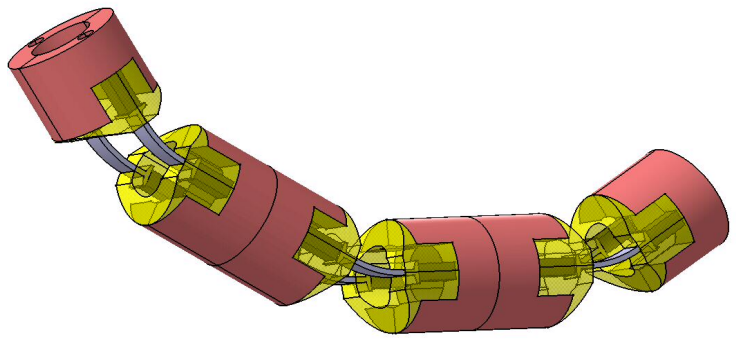

Fig. 11. Multi stage endoscope head.

reality and $67^{\circ} \mathrm{C}$ in simulation.

The experimental rotation range was measured from video acquisition (see figure 10). This range is $25^{\circ}$, a low value according to the $\theta_{\max }=54^{\circ}$ of the model prediction. This may be due to a bad choice in the active material: temperature transformation are in accordance with the model but the heat treatments performed on the blade have certainly provide lower plastic deformation than the $5 \%$ expected on classical NiTi material. The mechanical dynamic response is correlated to the temperature response of the blades. The test presented on figure 9 shows that cycling is possible at $0,05 \mathrm{~Hz}$. If the frequency is increased it will decrease the maximum rotation range. One can note the it is also possible to supply only one elementary stage at a time. In this case the response time of the actuator is increased due to a lower martensite phase transformation (convection cooling only).

\section{CONCLUSION AND PERSPECTIVES}

This study shows that the use of SMA antagonist blades associated with an integrated thermoelectric system is efficient for active endoscopy applications. The developed actuator can be improved by the use of a better NiTi alloy to obtain higher rotation angle. Our future work will consist in using several elementary stages electrically and mechanically interconnected to build a complete endoscope head with free space in its center for optical fibers and tools (see figure 11). Industrial or medical application are conceivable based on this work and could succeed in high technology systems.

\section{REFERENCES}

Abadie, J., N. Chaillet and C. Lexcellent (2002). An integrated shape memory alloy micro-actuator controlled by thermoelectric effect. Sensors and Actuators A: Physical A99(3), 297-303.
Abadie, J., N. Chaillet and C. Lexcellent (2004). Bending model of an integrated SMA microactuator. Journal of Intelligent Material Systems and Structures 15(8), 601-609.

Abadie, J., N. Chaillet, C. Lexcellent and A. Bourjault (1999). Thermoelectric control of shape memory alloy microactuator : a thermal model. In: Proc. of SPIE Smart Structures and Materials. Vol. 3667. Newport Beach CA USA. pp. $326-336$.

Benzaoui, H., C. Lexcellent, N. Chaillet, B. Lang and A. Bourjault (1997). Experimental study and modeling of a TiNi shape memory alloy wire actuator. Journal of Intelligent Material Systems and Structures 8(7), 619-629.

Bhattacharyya, A., D. Lagoudas, Y. Wang and K. Kinra (1995). On the role of thermoelectric heat transfer in the design of SMA actuators: theoretical modeling and experiment. In: Smart Mater. Struc.. Vol. 4. pp. 252-263.

Khan, M., D. Lagoudas and O. Rediniotis (2003). Thermoelectric SMA actuator: preliminary prototype testing. In: Proceedings of SPIE, Smart Structures and Materials. Vol. 5054. pp. 147155.

Lagoudas, D. and Z. Ding (1995). A modeling of thermoelectric heat transfert in shape memory alloy actuators : transient and multiple cycle solutions. In: International Journal of Engineering Science. Vol. 33(15). p. 2345.

Leclercq, S. and C. Lexcellent (1996). A general macroscopic description of the thermomechanical behavior of shape memory alloys. J. Mech. Phys. Solids 44(6), 953-980.

Semenyuk, V., S. Seelecke, J. Stockholm and A. Musolff (1998). The use of thermoelectric cooling for shape memory wire temperature control. In: Proc. of ECT' 98.

Szewczyk, J., V. de Sars, P. Bidaud and G. Dumont (2001). An active tubular polyarticulated micro-system for fexible endoscope. Lecture Notes in Control and Information Sciences 271, $179-188$.

Thrasher, M., A. Shahin, P. Meckl and D. Jones (1992). Thermal cycling of shape memory alloy wires using semiconductor heat pump modules. In: Fisrt European Conf. On Smart Structures and materials. Glasgow. 